\title{
Morphometric and quantitative characterization of atrial ganglion neurons from the intercaval region in dogs with dilated cardiomyopathy
}

\author{
[Caracterização morfométrica e quantitativa dos neurônios ganglionares atriais da faixa intercaval de cães com \\ cardiomiopatia dilatada] \\ A.A. Camacho ${ }^{1}$, R. Oliveira-Alves ${ }^{2}$, R.P. Klein ${ }^{3}$, M.G. Sousa ${ }^{4}$ \\ ${ }^{1}$ Faculdade de Ciências Agrárias e Veterinárias - UNESP \\ Via de Acesso Prof. Paulo Donato Castellane, s/n \\ 14884-900 - Jaboticabal, SP \\ ${ }^{2}$ Universidade Federal de Goiás - UFG - Goiânia, GO \\ ${ }^{3}$ Universidade Federal do Piauí - UFPI - Teresina, PI \\ ${ }^{4}$ Universidade Federal do Tocantins - UFT - Araguaína, TO
}

\begin{abstract}
The quantity, morphometry, and quality of atrial neurons from the intercaval region in dogs with dilated cardiomyopathy (DCM) were evaluated. Dogs with DCM had greater ganglion neurons than control dogs. The histologic evaluation of the ventricular myocardium and ganglion neurons confirmed DCM and showed the degeneration of ganglion neurons. Dogs with chronic DCM had a secondary cardioneuropathy owing to impaired parasympathetic neural control.
\end{abstract}

Keywords: dog, cardiomyopathy, histology, morphometry

\section{RESUMO}

Avaliaram-se quantitativa, morfométrica e qualitativamente os neurônios atriais da faixa intercaval de cães com cardiomiopatia dilatada (CMD). Os neurônios dos gânglios nervosos de cães com CMD eram maiores que os dos cães controle. A histopatologia do miocárdio ventricular e dos neurônios ganglionares confirmou a CMD e demonstrou evidente processo degenerativo neuronal ganglionar. Cães com CMD em fase crônica apresentavam cardioneuropatia secundária, provavelmente pela privação da inervação parassimpática cardíaca.

Palavras-chave: cão, miocardiopatia, histologia, morfometria

\section{INTRODUCTION}

Congestive dilated cardiomyopathy syndrome (DCM) is characterized by an increase in heart volume (cardiectasis) and, frequently, by the development of congestive heart failure (CHF). The disease is presented as a systolic contractile dysfunction and augmentation of end-systolic and end-diastolic volumes (Wynne and Braunwald, 1991; Tidholm and Jonsson, 2005). DCM is likely to be the common expression of myocardial lesions induced by several injuring agents. Some causes have been discussed, such as parvovirosis, carnitine or taurine deficiency, and doxorubicin cardiotoxicity, among others. Such causes are probably related to a secondary DCM (Sisson and Thomas, 1995).

The first cases of idiopathic DCM were reported in the late sixties (Ettinger et al. 1970). Today, this disease is worldwide known (Thomas, 1987). In general, DCM occurs in large breed dogs, as well as medium-sized dogs like Cocker Spaniels and Springer Spaniels (Tilley and Owen, 1985; Tidholm and Jonsson, 2005).

The disease may affect dogs from six months to eight years of age. Males are affected more often, 
and generally survive for six months after the onset of clinical signs. Cardiac histopathology has shown thinner myocardial fibers, which were separated by extracellular edema and connective tissue. Myocytolisis is also a common finding. In chronic cases, myofiber atrophy, fibrosis, and fat infiltration may be frequently observed (Van Vleet et al., 1981; Fox, 1988; Liu, 1988). Although the increased sympathetic drive is a known component in CHF owing to DCM, the role played by the parasympathetic nervous system is still unknown. According to Binkley et al. (1991), parasympathetic tone may be absent in dogs with experimentally-induced congestive heart failure. Therefore, it was hypothesized that dogs with DCM might present alterations in intracardiac parasympathetic autonomic nervous system. This study was carried out to evaluate the quantity, morphometry and quality of atrial neurons from the intercaval region in dogs with DCM.

\section{MATERIAL AND METHODS}

Fifteen dogs of each sex, including several breeds were studied. The animals were divided in two groups: DCM group with $10 \mathrm{dogs}$ of different ages and breeds presenting clinical signs compatible with idiopathic DCM and control group with five healthy mature mongrel dogs. Every dog underwent clinical examination in accordance with standard semiologic and laboratorial techniques. The results were transferred to the medical record of each dog for the constitution of groups.

Electrocardiogram (ECG) was recorded using a RFT electrocardiograph ${ }^{1}$, in accordance with standard ECG techniques for recording limb leads (I, II, III, aVR, aVL, and aVF). Paper speed was set at $50 \mathrm{~mm} / \mathrm{s}$ and calibration was defined as one milivolt per centimeter (Tilley, 1992). Lateral and ventrodorsal chest radiographs were obtained from dogs assigned to the DCM group to confirm dilatation of cardiac chambers. To acquire radiographs, a X-ray equipment ${ }^{2}$ was used, and an automatic machine ${ }^{3}$ was used to develop films.

\footnotetext{
${ }^{1}$ RFT 6 - Neck 4 (eletrocardiograph)

${ }^{2}$ Siemens - modelo RG 150/100 GL

${ }^{3}$ Runzomatic 130 automatic processor
}

After death, dogs were submitted to necropsy in order to confirm the diagnosis of DCM. Hearts from dogs of the DCM and control groups were submitted to gross pathology examination. Following, hearts were opened according to standard necropsy techniques and both atrial and ventricular fragments were collected for histopathologic evaluation, morphometry and quantification of atrial ganglion neurons (Köberle, 1959). Dogs of the DCM group were followed clinically until natural death. For the dogs assigned to the control group, euthanasia was performed with an intravenous overdose of sodium thiopental until conscience was lost and cardiorespiratory arrest occurred. Care was taken to avoid any discomfort for the animals during the procedure.

Fragments from the area between caudal vena cava and cranial vena cava (intercaval region) were collected from healthy dogs and dogs with DCM. Samples were fixed in buffered formalin $(\mathrm{pH}=7.2)$, dehydrated, embedded in paraffin, and cut in semi-serial $8 \mu \mathrm{m}$ sections (for each chosen section the following three sections were discarded up to the end of the paraffin block). The sections were stained with hematoxylin and eosin (HE), and exceptionally with Gomori's trichrome (GMS).

To count neurons, whose mean diameter is $32 \mu \mathrm{m}$, a light microscope ${ }^{4}$ endowed with a $10 \mathrm{x}$ ocular and 20x objective was used. The neurons inside atrial parasympathetic ganglion were quantified according to the technique proposed by Köberle (1959).

Morphometric analysis of atrial parasympathetic ganglion neurons was accomplished with the video plan $^{5}$ image analysis equipment. Under 230 times magnification, ten percent of each animal's microscope plates were examined. Morphometric analysis provided information regarding perimeter, maximal and minimal diameters, area, and volume of ganglion neurons.

To compare the densities of atrial parasympathetic ganglion neurons, as well as the morphometric data between DCM group and control group, an analysis of variance was performed.

\footnotetext{
${ }^{4}$ Carl Zeiss

${ }^{5}$ Kontron Elektronik
} 


\section{RESULTS}

The most common clinical signs in the dogs with DCM were exercise intolerance, lethargy, weakness, anorexia, syncope, moderate cough, and ascites. Variable duration and progression of clinical signs were seen among the animals. The combination of anamnesis, clinical signs, and physical examination findings was sufficient for a presumptive diagnosis of DCM. Pulse deficits or irregular auscultation provided clinical evidences of arrhythmias, either atrial fibrillation or ventricular premature beats. Furthermore, gallop rhythm with presence of low-frequency $\mathrm{S}_{3}$ and $\mathrm{S}_{4}$ cardiac sounds were listened in some cases. Systolic murmurs, however, were not frequently heard. In advanced cases, dyspnea, tachypnea, pulmonary crackles, congestion of mucous membranes and, rarely, a mild pink tinged frothy secretion coming from mouth and nares were also observed.

The most frequent ECG findings in dogs with DCM were sinus tachycardia, supraventricular arrhythmias (refractory atrial fibrillation), ventricular premature beats, as well as increased duration of P wave and QRS complex indicating cardiac chamber enlargement. Radiographic findings in dogs with DCM were the most characteristic of cardiac chamber enlargement. This method allowed to individually observe pulmonary and vascular congestion, especially in the most advanced cases. Three animals presented pleural effusion or ascites with no respiratory signs.

Post-mortem examination showed generalized cachexia in dogs with DCM. There was cardiectasis, pulmonary congestion, and mild fluid in the pericardial sac. Cardiac chambers, especially the ventricles, were enlarged, and there was left ventricular eccentric hypertrophy. The liver, spleen, and regional lymph nodes were congested, and a bloody fluid was present in the abdomen.

The histologic examination of the myocardium of DCM dogs showed muscular fibers with increased volume and loss of myofibrils visualization (Fig. 1-A). In some cases, there was either degeneration or destruction of fibers, indicating tissue necrosis. The atrial ganglia from the intercaval region of DCM dogs (Fig. 1-C; 1D) had increased volume, vacuolization, tumefaction with proliferation of satellite cells (Fig. 2-B), cytoplasmic inclusions, weak neuropils and, sometimes, an infiltrate suggesting ganglionitis. There was a significant difference between groups regarding the quantity of atrial ganglion neurons from the intercaval region (Table 1), showing a higher neuronal density in the intercaval region of DCM group. Moreover, the video plan image evaluation showed that the atrial neurons of DCM dogs (Fig. 1-C; 1-D) had a higher area, maximal diameter, minimal diameter, perimeter, and volume in comparison with healthy dogs (Fig. 1B) from control group (Table 1).

\section{DISCUSSION}

In this study, the diagnosis of DCM was based on clinical history, clinical signs, and results of physical and laboratorial examinations. The diagnosis was confirmed by pathologic evaluation and histopathologic results. It is an axiomatic disease for its clinical alterations, electrocardiographic findings such as supraventricular or ventricular arrhythmias, and cardiac enlargement observed on radiographs.

Table 1. Mean values $(\mathrm{X} \pm \mathrm{SD})$ of neural count $^{1}$ and Video Plan morphometric evaluation of atrial parasympathetic ganglion neurons of the intercaval region in healthy control dogs and dogs with dilated cardiomyopathy (DCM).

\begin{tabular}{|c|c|c|c|c|c|c|c|}
\hline \multirow[b]{2}{*}{ Group } & \multirow[b]{2}{*}{$\mathrm{N}$} & \multirow[b]{2}{*}{ Neurons } & \multirow[b]{2}{*}{$\begin{array}{l}\text { Perimeter } \\
(\mu \mathrm{m})\end{array}$} & \multicolumn{2}{|c|}{ Diameter } & \multirow[b]{2}{*}{$\begin{array}{l}\text { Area } \\
\left(\mu \mathrm{m}^{2}\right)\end{array}$} & \multirow{2}{*}{$\begin{array}{l}\text { Volume } \\
\left(\mu \mathrm{m}^{3}\right)\end{array}$} \\
\hline & & & & $\begin{array}{c}\text { Maximal } \\
(\mu \mathrm{m})\end{array}$ & $\begin{array}{c}\text { Minimal } \\
(\mu \mathrm{m})\end{array}$ & & \\
\hline DCM & 10 & $6583 \pm 688 \mathrm{a}$ & $93.3 \pm 3 a$ & $35.6 \pm 1 \mathrm{a}$ & $22.7 \pm 0.9 \mathrm{a}$ & $619.7 \pm 48 \mathrm{a}$ & $\begin{array}{c}1751.9 \pm 201 \\
\mathrm{a}\end{array}$ \\
\hline CONTROL & 5 & $2937 \pm 915 b$ & $69.8 \pm 3 b$ & $27.0 \pm 1 b$ & $16.2 \pm 0.7 b$ & $331.0 \pm 35 b$ & $698.7 \pm 112 b$ \\
\hline
\end{tabular}

${ }^{1}$ Köberle (1959). N: Number of animals.

Means in the same column with no common letter differ $(\mathrm{P}<0.01)$ 

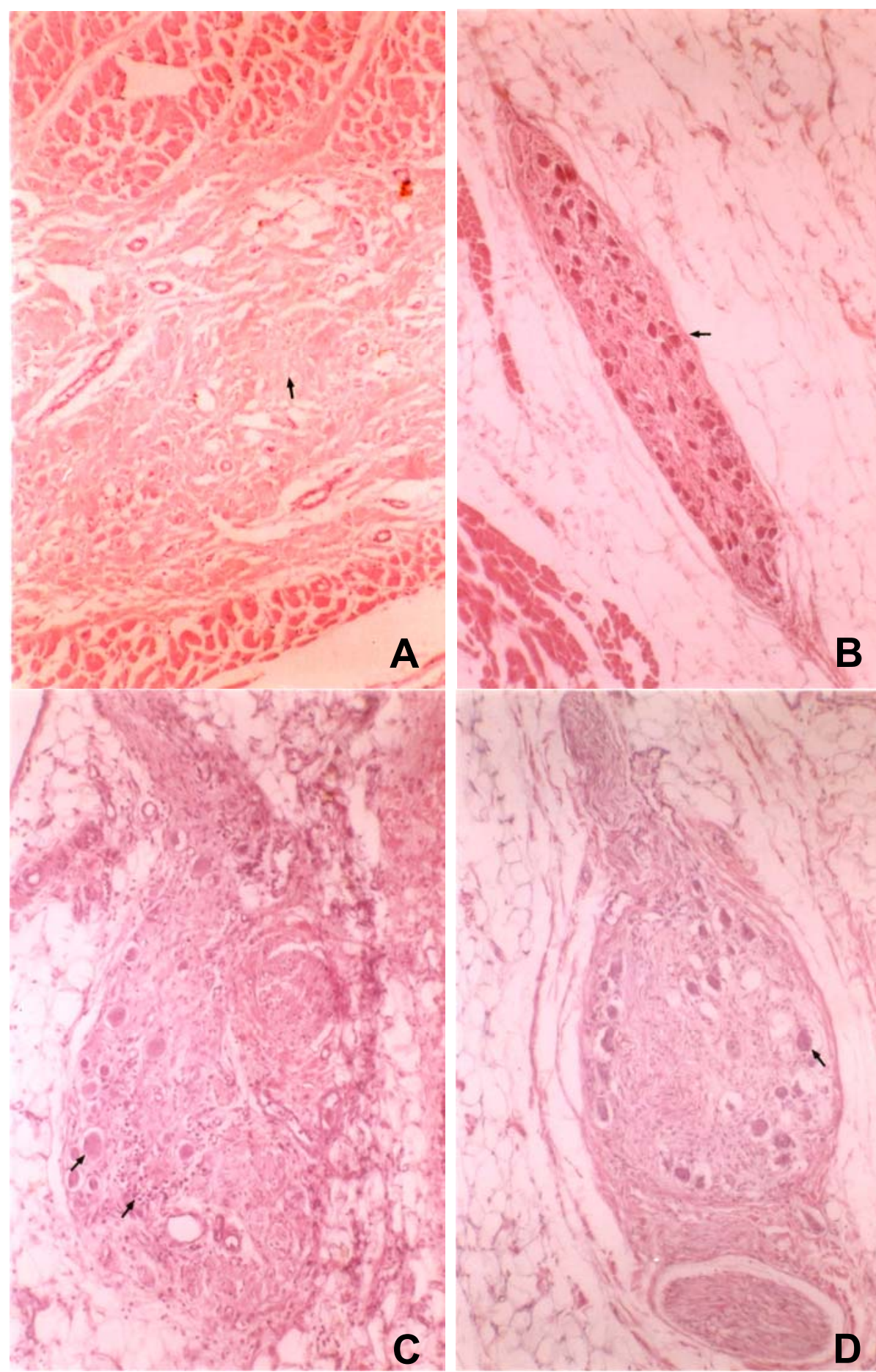

Figure 1. Photomicrographs of myocardial and intercaval sections stained with hematoxylin and eosin. (A) Left ventricular myocardium section showing degenerated fibrils (arrow) (100x); (B) Ganglion neurons from a normal dog showing a dense neuropil (arrow) (200x); (C) Atrial ganglion from a dog with dilated cardiomyopathy showing a mononuclear infiltrate (right arrow) and degenerated neurons with increased volume (left arrow) (100x); (D) Atrial ganglion showing neurons with increased volume (arrow) in a dog with dilated cardiomyopathy (100x). 

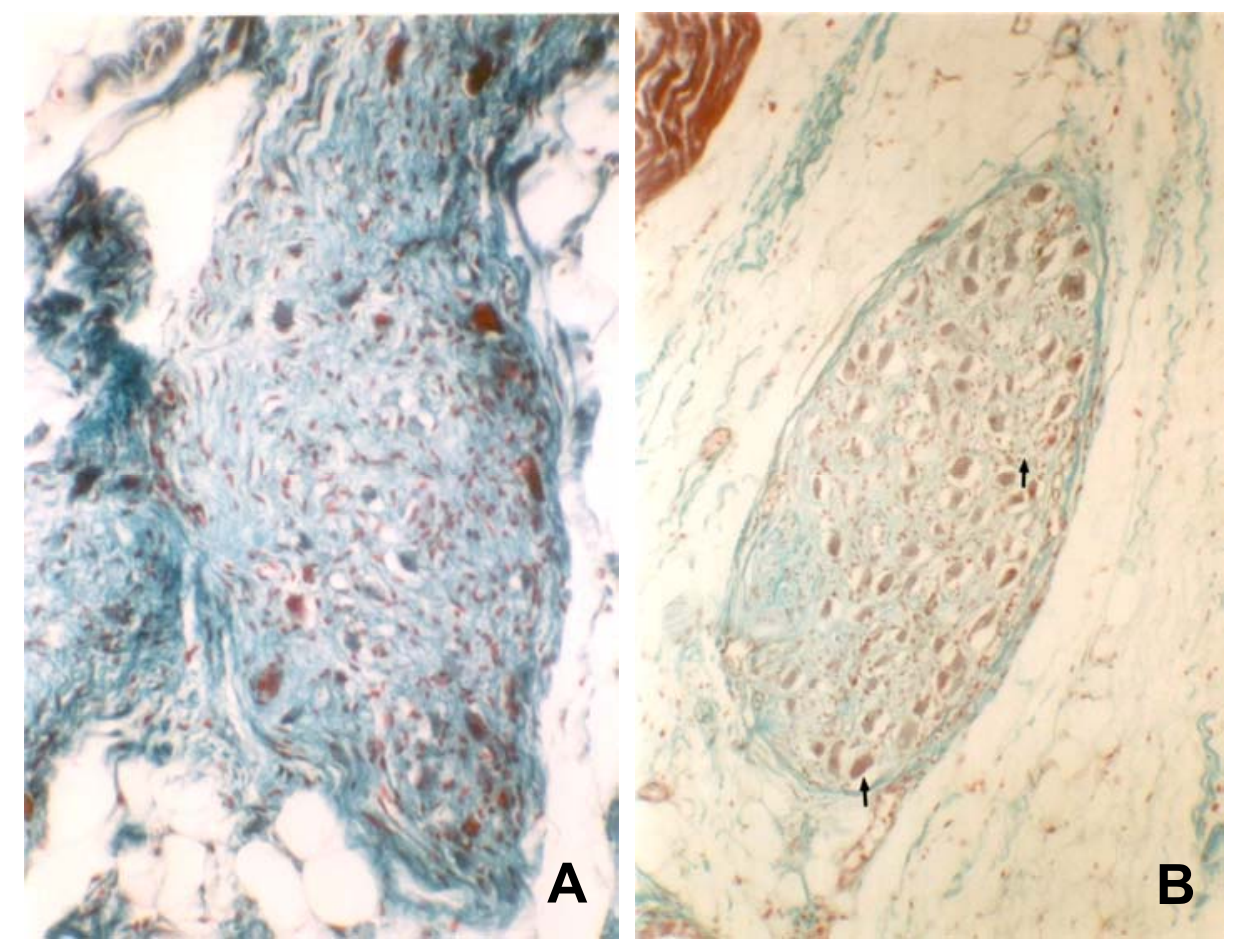

Figure 2. Photomicrographs of intercaval sections stained with Gomori's trichrome. (A) Atrial ganglion of a normal dog (200x); (B) Atrial ganglion of a dog with dilated cardiomyopathy showing degenerated neurons with little pigmentation (bottom arrow), a weak neuropil, and proliferation of satellite cells (top arrow) (200x).

Although the electrocardiogram lacks specificity to determine the size, thickness, and contractility of the myocardial wall, it was an important method for the definitive diagnosis of arrhythmias. In the conditions of this study, electrocardiograms from dogs with DCM have also supported the initial hypothesis of a cardioneuropathy secondary to idiopathic DCM. Thereby, the presence of refractory tachyarrhythmias substantiated the possibility of depleted atrial neurons leading to parasympathetic dysfunction.

The main gross pathologic findings in DCM dogs were cachexia, presence of pulmonary congestion and edema, cardiectasis with thinnerthan-normal cardiac walls, as well as eccentric hypertrophy in some cases. Such findings are in agreement with other studies that had described cardiac alterations seen at necropsy as unspecific, and sometimes not reflecting the diminished myocardial contractility (Van Vleet et al., 1981; Thomas, 1987; Fox, 1988; Liu, 1988).
The intercaval region was studied based on a previous hypothesis (Harpster, 1983; Calvert, 1995; Hamlim, 1995) that supraventricular arrhythmias occurring in DCM were mainly due to the dilatation and distension of atrial chambers leading to a constant irritation. Since cases of DCM have dilatation of cardiac free walls, the intercaval region might represent the dilated atrial area reported previously.

Dogs from DCM group had more intercaval neurons in comparison to control group dogs. Such neuronal count demanded the study of the morphometry of the neurons, another aspect of this research. There was an interest in knowing the morphometric feature of the neurons. The results demonstrated that the perimeter, maximal and minimal diameters, area, and volume of neurons in dogs with DCM were always greater than those of control dogs. Because the neurons of DCM dogs were degenerated and swollen, and the semi-serial sections achieved the maximal thickness of $32 \mu \mathrm{m}$, it is likely that neurons were cut more than once, resulting in the fake impression of a greater number of neurons in 
DCM dogs than in healthy animals. This finding reinforced the importance of Video Plan morphometry in future cytomorphometric studies of the heart (Hamilton and Allen, 1995).

The increased mean values in the aforementioned morphometric parameters are in agreement with the histopathologic findings that indicated an increased volume, vacuolization, tumefaction with proliferation of satellite cells, cytoplasmic inclusions, neural ganglia with weak neuropils and ganglionitis. Such findings may be traced to some loss of parasympathetic function within the heart of dogs with DCM. In accordance with Davila et al. (1989), cardiac parasympathetic abnormalities are preceded by myocardial damage and ventricular dilatation and/or hypertrophy, which may lead to wrong interpretations of diagnosis, prognosis, treatment, and clinical monitoring of patients.

The findings of clinical examination, morphometry, and histopathology in this research suggest that dogs with chronic DCM presenting signs of $\mathrm{CHF}$ underwent a degenerative process of the parasympathetic nervous system. Therefore, these dogs had an impaired cardiac parasympathetic innervation, which seems to be a secondary cardioneuropathy in this case. That is supported by the demonstration of refractory arrhythmias (Tilley, 1992) and a higher concentration of serum catecholamines in dogs with dilated cardiomyopathy (Van Vleet et al., 1981), thereby confirming the initial hypothesis of cardiac parasympathetic dysfunction.

\section{CONCLUSIONS}

The degenerated atrial ganglion neurons observed in histopathology, in conjunction with increased morphometric parameters provided information that chronic DCM tends to progress to a clinical manifestation of cardioneuropathy due to parasympathetic disautonomy.

\section{REFERENCES}

BINKLEY, P.F.; NUNZIATA, E.; HAAS, G.J. et al. Parasympathetic withdrawal is an integral component of autonomic imbalance in congestive heart failure: demonstration in human subjects and verification in a paced canine model of ventricular failure. J. Am. Coll. Cardiol., v.18, p.464-472, 1991.
CALVERT, C.A. Canine cardiomyopathy. In: TILLEY, L.P. Manual of canine and feline cardiology. 2.ed., Philadelphia: Saunders, 1995. p.145-170.

DAVILA, D.F.; ROSSEL, O.; DONIS, J.H. Cardiac parasympathetic abnormalities. Cause or consequence of Chagas' heart disease? Parasitol. Today, v.5, p.327329, 1989.

ETTINGER, S.J.; BOLTON, G.R.; LORD, P.F. Idiopathic cardiomyopathy in the dog. J. Am. Vet. Med. Assoc., v.156, p.1225, 1970.

FOX, P.R. Canine myocardial disease. In: FOX, P.R. (Ed.) Canine and feline cardiology. New York: Churchill Livingstone, 1988. p.467-493.

HAMLIM, R.L. What is the best heart rate for a dog in atrial fibrilation? In: ANNUAL VETERINARY MEDICAL FORUM, 13., 1995, Orlando. Proceedings... Orlando, 1995. p.325-326.

HAMILTON, P.W.; ALLEN, D.C. Morphometry in histopathology. J. Pathol., v.175, p.369-379, 1995.

HARPSTER, N.Y. Boxer cardiomyopathy. In: KIRK, R.W. (Ed.) Current veterinary therapy. Philadelphia: Saunders, 1983. p.329-337.

KÖBERLE, F. Cardiopathy parasympathicopriva. Münch Med. Wochenschr., v.101, p.1308-1310, 1959.

LIU, S.K. Cardiovascular pathology. In: FOX, P.R. (Ed.) Canine and feline cardiology. New York: Churchill Livingstone, 1988. p.650-652.

SISSON, D.D.; THOMAS, W.P. Myocardial diseases. In: ETTINGER, S.J.; FELDMAN, E.C. (Ed.). Textbook of veterinary internal medicine. Philadelphia: Saunders, 1995. p.995-1032.

THOMAS, W.P. Myocardial diseases of the dog. In: BONAGURA, J.D. (Ed.) Contemporary issues small animal practice: cardiology. New York: Churchill Livingstone, 1987. v.7, p.117-155.

TIDHOLM, A.; JONSSON, L. Histologic characterization of canine dilated cardiomyopathy. Vet. Pathol., v.42, p.1-8, 2005.

TILLEY, L.P.; OWEN, J.M. Manual of small animal cardiology. New York: Churchill Livingstone, 1985. $447 \mathrm{p}$.

TILLEY, L.P. Essential of canine and feline electrocardiography. 2.ed. Philadelphia: Lea \& Febiger, 1992. 484p.

VAN VLEET, J.F.; FERRANS, V.J.; WEIRICH, W.E. Pathologic alterations in congestive cardiomyopathy of dogs. Am. J. Vet. Res., v.42, p.416-424, 1981.

WYNNE, J.; BRAUNWALD, E. Cardiomiopatias e Miocardites. In: BRAUNWALD, E. (Ed.) Tratado de medicina cardiovascular. 3.ed. São Paulo: Roca, 1991. p.1475-537. 